(2) Open Access Full Text Article

\title{
Comparative analysis of corneal morphological changes after transversal and torsional phacoemulsification through $2.2 \mathrm{~mm}$ corneal incision
}

\author{
This article was published in the following Dove Press journal: \\ Clinical Ophthalmology \\ 7 January 2013 \\ Number of times this article has been viewed
}

\author{
Ahmed Assaf \\ Maged Maher Roshdy \\ Ophthalmology Department, \\ Ain Shams University, Cairo, Egypt
}

Correspondence: Maged Maher Roshdy 21 I Elhegaz St, Elhegaz Sq, Heliopolis, Cairo, Egypt

Tel +20 I 22 28I I230

Fax +20 226247575

Email dr_maged_roshdy@med.asu.edu.eg
Purpose: This paper compares and evaluates the corneal morphological changes occurring after cataract surgery through a $2.2 \mathrm{~mm}$ corneal incision. We use two platforms for comparison and evaluation, transversal and torsional phacoemulsification.

Patients and methods: This study includes 139 consecutive cataractous eyes (nuclear color 2-4, according to the Lens Opacities Classification System III [LOCSIII]) of 82 patients undergoing cataract surgery through a $2.2 \mathrm{~mm}$ corneal incision. Two different phacoemulsification platforms were used and assigned randomly: we used the WhiteStar Signature ${ }^{\circledR}$ system with the Ellips $^{\mathrm{TM}} \mathrm{FX}$ transversal continuous ultrasound (US) mode for group I (mean age: $65.33 \pm 6.97$ years), and we used the Infiniti ${ }^{\circledR}$ system with the OZil ${ }^{\circledR}$ Intelligent Phaco (IP) torsional US mode for group II (mean age: $64.02 \pm 7.55$ years). The corneal endothelium and pachymetry were evaluated preoperatively and at 1 month postoperatively. Incision size changes were also evaluated.

Results: All surgeries were uneventful. Before intraocular lens implantation, the mean incision size was $2.24 \pm 0.06 \mathrm{~mm}$ in both groups $(P=0.75)$. In terms of corneal endothelial cell density, neither preoperative (I vs II: $2304.1 \pm 122.5 \mathrm{cell} / \mathrm{mm}^{2}$ vs $2315.6 \pm 83.1 \mathrm{cell} /$ $\mathrm{mm}^{2}, P=0.80$ ) nor postoperative (I vs II: $2264.1 \pm 124.3$ cell $/ \mathrm{mm}^{2}$ vs $2270.3 \pm 89.9$ cell/ $\mathrm{mm}^{2}, P=0.98$ ) differences between the groups were statistically significant. The mean endothelial cell density loss was $1.7 \% \pm 1.6 \%$ and $2.0 \% \pm 1.4 \%$ in groups I and II, respectively. Furthermore, no significant differences between groups I and II were found preoperatively $(P=0.40)$ and postoperatively $(P=0.68)$ in central pachymetry. With surgery, the mean increase in central pachymetry was $28.1 \pm 23.6 \mu \mathrm{m}$ and $24.0 \pm 24.0 \mu \mathrm{m}$ in groups I and II, respectively $(P=0.1)$.

Conclusion: Ellips ${ }^{\mathrm{TM}} \mathrm{FX}$ transversal and $\mathrm{OZi1}{ }^{\circledR}$ IP torsional phacoemulsification modes are safe for performing cataract surgery, inducing minimal corneal thickness and endothelial changes.

Keywords: cornea, endothelium, transversal phacoemulsification, torsional phacoemulsification, Ellips $^{\mathrm{TM}} \mathrm{FX}, \mathrm{OZil}^{\circledR}$ IP

\section{Introduction}

The main objectives of modern phacoemulsification (phaco) technology are the reduction of ultrasound (US) power and improved efficiency. ${ }^{1}$ Interrupted phaco modes, improved pump systems, chopping techniques, and vacuum-assisted phaco have reduced the amount of energy needed to remove a cataract and, therefore, the potential associated risks. ${ }^{1,2}$ However, US power required for traditional or longitudinal phaco continues to be a risk factor for endothelial cell loss and tissue damage. ${ }^{3}$ Through the use of improved phaco technologies, 
recent studies on cataract surgery have demonstrated a reduction in corneal endothelial cell loss after phaco..$^{4-11}$

In an attempt to increase US efficiency during phaco cataract surgery, torsional phaco technology was introduced in 2005. In traditional phaco, the longitudinal movement of the phaco tip pushes nuclear fragments away with each forward stroke, although interrupted US has the supposed advantage of allowing retraction of the pushed nuclear fragments back toward the phaco tip. Furthermore, due to the jackhammer effect, the emulsifying power of longitudinal phaco is only effective during the forward movement of the tip. Conversely, the lateral tip movement of torsional phaco shears the lens material while moving in both directions without a repellent force. It also uses a lower frequency (32 MHz) than traditional phaco (40 MHz), allowing for $20 \%$ energy conservation. As such, torsional technology represents a significant improvement in the emulsifying efficiency of US during phaco. ${ }^{12,13}$ Torsional US can also be mixed, intermittently, with a quantum of longitudinal phaco. This is commercially known as $\mathrm{OZil}^{\circledR}$ Intelligent Phaco (IP) (Alcon Laboratories, Fort Worth, TX, USA), whereby the quantum is liberated at a threshold vacuum in a duration ranging from 10 to 20 milliseconds. IP aims to maximize torsional US efficacy by keeping the nuclear fragments in the ideal shearing plane. ${ }^{14}$

In addition to torsional technology, transversal US technology is a new form of phaco. The transversal US model, Ellips $^{\text {TM }}$ (Abbott Medical Optics, Santa Ana, CA, USA), was developed to reduce the repulsion that commonly occurs with longitudinal phaco. Ellips ${ }^{\mathrm{TM}}$ simultaneously generates lateral and longitudinal motions at a working frequency of $28 \mathrm{kHz}$; thus, the phaco tip moves in an elliptical motion, promoting an optimization of efficiency by emulsifying lens matter in more than one direction. Moreover, the accompanying longitudinal component adds the jackhammering effect to transversal US efficiency, constantly maintaining the nuclear fragments at the ideal shearing plane in front of the phaco tip. ${ }^{15}$ The transversal technology can also be used with a straight or curved tip, and the Ellips ${ }^{\mathrm{TM}}$ model can work in a continuous or hyperpulse mode with different duty cycles. ${ }^{16}$ Recently, Ellips ${ }^{\mathrm{TM}}$ FX (Abbott Medical Optics), a further hardware and software modification on the previous version, has been developed for a working frequency of $38 \mathrm{kHz}$ (a $45 \%$ increase on the previous version) and a stroke length three times larger (longitudinal and lateral stroke length ratio is 1:1) than the previous version.

Existing studies have experimentally compared torsional and transversal phaco systems in terms of vacuum, surge, and thermal effect. ${ }^{15-17}$ Furthermore, Christakis and Braga-Mele ${ }^{5}$ recently compared the clinical outcomes obtained after the same surgeon performed cataract surgery with phaco, using three different systems: WhiteStar Signature $^{\circledR}$ Ellips ${ }^{\text {TM }}$ FX (transversal), Infiniti ${ }^{\circledR} \mathrm{OZil}^{\circledR}$ IP (torsional), and Stellaris ${ }^{\circledR}$ (Bausch and Lomb, Rochester, NY, USA) (longitudinal). These authors evaluated the phaco needle time, chatter, followability, the anterior chamber stability, the level of corneal edema, and the 1-day postoperative visual acuity. However, to date, no comparisons between torsional and transversal phaco have been reported in terms of corneal endothelial changes. Hence, the aim of this study was to compare and evaluate the corneal morphological changes, including endothelial modifications, as an indicator of safety for cataract surgery through a $2.2 \mathrm{~mm}$ corneal incision. In this study, we compared and evaluated the transversal and torsional phaco platforms.

\section{Materials and methods Patients}

This study included 139 consecutive cataractous eyes of 82 patients undergoing cataract surgery through a $2.2 \mathrm{~mm}$ corneal incision. The inclusion criteria were patients of 45 years or older and the presence of a senile cataract graded as nuclear color (NC) 2-4, according to the Lens Opacities Classification System III (LOCSIII). ${ }^{18}$ The exclusion criteria were patients with glaucoma, corneal opacities, cornea guttata, abnormal iris, macular degeneration or retinopathy, previous posterior segment surgery, a corneal endothelial cell density (ECD) of less than 1900 cell $/ \mathrm{mm}^{2}$, neuro-ophthalmic disease, or a history of ocular inflammation. All volunteers were adequately informed and signed a consent form. The study adhered to the tenets of the Declaration of Helsinki, and the study was approved by the local ethical committee.

One of the two different phaco platforms was assigned to be used with each eye included in this study. Random assignment was performed by coin toss. Accordingly, two groups were differentiated: group I included eyes undergoing phaco via the WhiteStar Signature ${ }^{\circledR}$ platform using the Ellips ${ }^{\mathrm{TM}}$ FX transversal continuous ultrasound mode with the $0.9 \mathrm{~mm}$ curved microtip, and group II included eyes undergoing phaco via the Infiniti ${ }^{\circledR}$ platform using the OZil ${ }^{\circledR}$ IP torsional phaco with the $0.9 \mathrm{~mm} / 45^{\circ}$ Kelman tip.

\section{Examination protocol}

Preoperatively, all patients had a full ophthalmological examination, including evaluation of the refractive status, uncorrected and corrected distance visual acuity testing 
(Snellen optotypes and decimal notation), slit lamp examination, and Goldmann applanation tonometry and fundoscopy. Besides these basic clinical tests, corneal endothelial cell analysis and central corneal thickness (CCT) measurements were performed (EM-3000; Tomey, Erlangen, Germany). Corneal endothelial analysis included the measurement and recording of the ECD, the coefficient of variation $(\mathrm{CV})$, and the hexagonality. Patients were also evaluated during the follow-up at 1 day and 1 month after surgery. At 1 day after surgery, intraocular pressure and the integrity of the anterior segment were evaluated. The corneal endothelium and pachymetry were evaluated one month after surgery.

\section{Surgery}

All surgeries were performed by the same surgeon (AA), using a standard mini-incision of the sutureless microcoaxial phaco technique. In all cases, a corneal incision of $2.2 \mathrm{~mm}$ was planned, followed by a paracentesis of $1.2 \mathrm{~mm}$. After injection of the cohesive ophthalmic viscoelastic device (Healon ${ }^{\circledR} \mathrm{GV}$; Abbott Medical Optics) in the anterior chamber, a curvilinear rhexis of 5-5.5 mm was performed. After hydrodissection, nucleus disassembly was started using the quick-chop technique, impaling the curved phaco-tip in the central part of the nucleus $(1-1.5 \mathrm{~mm})$. This was followed by vertical chopping of the nucleus with the Tobias Neuhann chopper (Geuder GmbH, Heidelberg, Germany). The incision size change was tested using the Tsuneoka micro-coaxial incision gauge (Asico, Westmont, IL, USA) after completion of the cortical cleaning and prior to intraocular lens (IOL) implantation. One-piece acrylic IOLs (Tecnis ${ }^{\circledR} 1$ ZCB00; Abbott Medical Optics) were implanted in all cases. The wound seal was confirmed at the end of the surgery by a negative Seidel test.

Settings for the Infiniti ${ }^{\circledR}$ platform (torsional) were as follows: the power was set at $100 \%$ linear torsional continuous US amplitude; the IP power delivery option was activated to produce a 10 millisecond longitudinal phaco pulse when $95 \%$ vacuum was reached; the flow rate was $28 \mathrm{~mL} / \mathrm{min}$, with dynamic rise of +1 ; the vacuum was set at $350 \mathrm{mmHg}$; and the bottle height was $108 \mathrm{~cm}$. Settings for the WhiteStar Signature ${ }^{\circledR}$ platform (transversal) were as follows: the power of the Ellips ${ }^{\mathrm{TM}} \mathrm{FX}$ was set at $100 \%$ linear continuous transversal US; the aspiration rate was set at 28 and $26 \mathrm{~mL} / \mathrm{min}$ before and after occlusion, respectively; vacuum parameters were set at a maximum of $320 \mathrm{mmHg}$; the chamber stabilization environment (CASE) vacuum was set at $280 \mathrm{mmHg}$; CASE time was set at 500 milliseconds for NC 2 and at 800-1000 milliseconds for NC 3 and 4; and the bottle height was $67 \mathrm{~cm}$.

The same postoperative treatment was administered to all patients. This included: using moxifloxacin $\mathrm{HCl} 0.5 \%$ (Vigamox ${ }^{\circledR}$; Alcon Laboratories) eye drops three times per day for two weeks; rimexolone $1 \%$ (Vexol $^{\circledR}$; Alcon Laboratories) eye drops three times per day for 1 week, then twice per day for the following 2 weeks; tobramycin-dexamethasone (TobraDex ${ }^{\circledR}$; Alcon Laboratories) eye ointment once at bedtime for 2 weeks.

\section{Statistical analysis}

SPSS statistics software package (v 19.0) for Windows (IBM Corporation, Armonk, NY, USA) was used for statistical analysis. Normality of all data samples was first evaluated by means of the Kolmogorov-Smirnov test. When parametric analysis was possible, the Student $t$-test for paired data was used for comparisons between preoperative and postoperative examinations, and the Student $t$-test for unpaired data was used for the comparison between groups. When parametric analysis was not possible, the Wilcoxon rank-sum test was applied to assess the significance of differences between preoperative and postoperative data, and the Mann-Whitney test was applied for the comparison between groups, in all cases using the same level of significance $(P<0.05)$. Before the start of the study and according to our previous experience, we estimated that a sample size of 64 eyes per group would be required to detect a mean difference of 10 cell $/ \mathrm{mm}^{2}$ between both groups, with a standard deviation of 20 . Power of the test was set to 0.8 with a significance level of 0.05 .

We certify that all applicable institutional and governmental regulations concerning the ethical use of human volunteers were followed during this research.

\section{Results}

The total number of eyes included in this study was 150 of 88 patients (group I, 85 eyes; group II, 65 eyes). Six patients (11 eyes: six in group I and five in group II) did not complete the postoperative follow-up examinations and were excluded from the study. Therefore, the data used for the statistical analysis included 139 eyes of 82 patients: 79 eyes in group I and 60 eyes in group II. The mean age \pm SD was $65.3 \pm 7.0$ and $64.0 \pm 7.6$ years in groups I and II, respectively. No statistically significant differences in age were detected between groups (Mann-Whitney test: $P=0.29$ ). According to the LOCSIII, in group I, 29 eyes presented an NC 2 cataract, 41 eyes presented an NC 3 cataract, and nine eyes presented an NC 4 cataract. 
In group II, a similar distribution of cataract types, according to the LOCSIII, was found: 23 eyes with an NC 2 cataract, 30 eyes with an NC 3 cataract, and seven eyes with an NC 4 cataract.

\section{Intraoperative and early postoperative changes}

All surgeries were uneventful. Intraoperatively, we observed improved followability with less chattering of free nuclear fragments in both systems. No incisional corneal burns were observed. Before IOL implantation, the mean size of the main incision was $2.24 \pm 0.06 \mathrm{~mm}$ in both groups, with no statistically significant differences between them (Mann-Whitney test: $P=0.75$ ). On the first postoperative day, the slit lamp examination showed mild stromal corneal folds in both groups with complete resolution at an average of 7 days, ranging from 4 to 10 days.

\section{Corneal endothelial changes}

Table 1 summarizes the corneal endothelial changes for groups I and II, occurring 1 month after surgery. As shown, we found significant changes in the three parameters analyzed (ECD, CV, and hexagonality) in both groups (Wilcoxon test: $P \leq 0.02$ ) 1 month after surgery, except for the hexagonality in group II. The mean postoperative decrease in ECD was $40.0 \pm 37.5 \mathrm{cell} / \mathrm{mm}^{2}$ and $45.3 \pm 31.7 \mathrm{cell} / \mathrm{mm}^{2}$ in groups I and II, respectively. No statistically significant differences in ECD were found between the groups preoperatively (Mann-Whitney test: $P=0.80$ ) and postoperatively (Mann-Whitney test: $P=0.98$ ). In relation to preoperative values (Figure 1), group I showed a mean endothelial cell loss of $1.7 \% \pm 1.6 \%$, whereas group II showed a loss of $2.0 \% \pm 1.4 \%$ (Mann-Whitney test: $P=0.29$ ). Regarding CV, no statistically significant differences were found between groups preoperatively (Mann-Whitney test: $P=0.82$ ) and postoperatively (Mann-Whitney test: $P=0.96$ ). Likewise, hexagonality did not differ significantly between groups before (Mann-Whitney test: $P=0.35$ ) and after (MannWhitney test: $P=0.97)$ surgery.

\section{Corneal thickness changes}

The preoperative CCT was $534.5 \pm 29.3 \mu \mathrm{m}$ and $536.9 \pm 26.2 \mu \mathrm{m}$ in groups I and II, respectively (MannWhitney test: $P=0.40)$. The postoperative CCT was $562.6 \pm 33.7 \mu \mathrm{m}$ (increased by $28.1 \pm 23.6 \mu \mathrm{m}$ ) and $560.9 \pm 29.9 \mu \mathrm{m}$ (increased by $24.0 \pm 24 \mu \mathrm{m}$ ) in groups I and II, respectively (Mann-Whitney test: $P=0.68$ ). Thus, the postoperative increase in CCT was similar in both groups (Mann-Whitney test: $P=0.10$ ). The central pachymetry change with surgery was statistically significant in both groups (Wilcoxon test: $P<0.01$ ).

\section{Discussion}

Technological advances in phaco have made cataract removal safer and more efficient by reducing phaco energy and duration. Torsional and transversal phaco modes are the results of these technological advances. Several studies have confirmed and reported the superiority of torsional phaco over longitudinal phaco in terms of needle time, chatter, followability, corneal

Table I Summary of the corneal endothelial changes analyzed by specular microscopy in the two groups analyzed in the current study: group I, eyes undergoing phacoemulsification using the WhiteStar Signature ${ }^{\circledR}$ platform and the Ellips ${ }^{\mathrm{TM}}$ FX (Abbott Medical Optics, Santa Ana, CA, USA) transversal continuous ultrasound mode; and group II, eyes undergoing phacoemulsification using the Infiniti ${ }^{\circledR}$ $\mathrm{OZi}^{\circledR}$ Intelligent Phaco (Bausch and Lomb, Rochester, NY, USA) torsional ultrasound mode

\begin{tabular}{|c|c|c|c|}
\hline \multirow[t]{2}{*}{ Endothelial parameters } & \multicolumn{2}{|c|}{ Mean (SD), median (range) } & \multirow{2}{*}{$\begin{array}{l}P \text {-value } \\
\text { (Wilcoxon test) }\end{array}$} \\
\hline & Preoperative & I month postoperative & \\
\hline \multicolumn{4}{|l|}{ Group I } \\
\hline \multirow[t]{2}{*}{$\mathrm{ECD}\left(\mathrm{cell} / \mathrm{mm}^{2}\right)$} & $2304.1(122.5)$ & $2264.1(129.3)$ & $<0.01$ \\
\hline & $2303.0(1950-2588)$ & $2279.0(1924-2567)$ & \\
\hline \multirow[t]{2}{*}{$C V$} & $38.2(3.5)$ & $38.7(3.2)$ & 0.02 \\
\hline & $38.0(33-45)$ & $39.0(31-46)$ & \\
\hline \multirow{2}{*}{ HEX (\%) } & $39.7(3.1)$ & $38.7(3.3)$ & $<0.01$ \\
\hline & $39.0(33-47)$ & $39.0(33-45)$ & \\
\hline \multicolumn{4}{|l|}{ Group II } \\
\hline \multirow{2}{*}{$\mathrm{ECD}\left(\mathrm{cell} / \mathrm{mm}^{2}\right)$} & $2315.6(83.1)$ & $2270.3(89.9)$ & $<0.01$ \\
\hline & $2318.0(2067-2466)$ & $2270.0(1990-2450)$ & \\
\hline \multirow[t]{2}{*}{$\mathrm{CV}$} & $38.0(3.2)$ & $38.9(2.6)$ & $<0.01$ \\
\hline & $38.0(33-45)$ & $39.0(33-44)$ & \\
\hline \multirow[t]{2}{*}{ HEX (\%) } & $39.1(3.2)$ & $38.6(3.1)$ & 0.07 \\
\hline & $39.0(33-45)$ & $39.0(32-45)$ & \\
\hline
\end{tabular}

Abbreviations: SD, standard deviation; ECD, endothelial cell density; CV, coefficient of variation; HEX, hexagonality. 


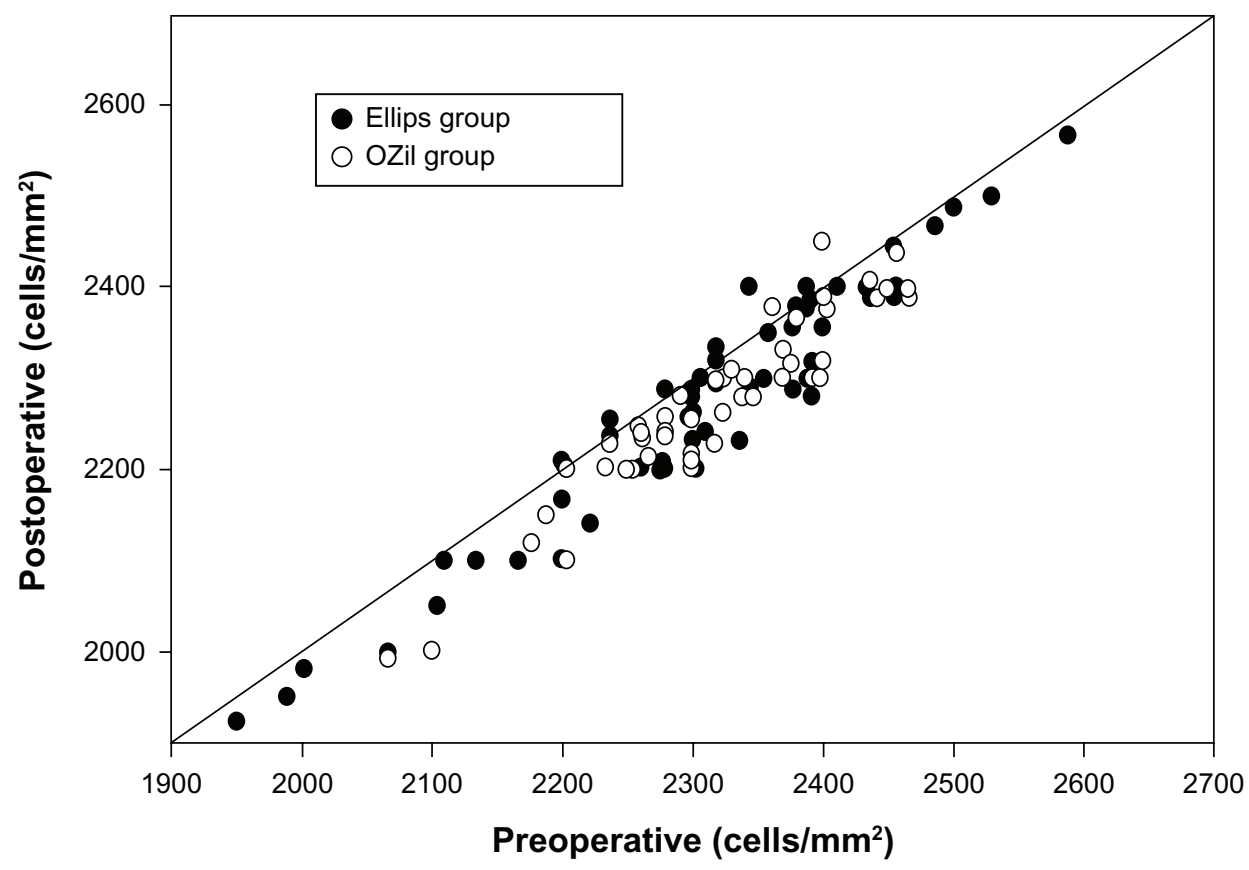

Figure I Scatter diagram of postoperative endothelial cells in relation to preoperative values in the two groups analyzed in the current study: group I, transversal phaco with Ellips $^{\text {TM }}$ FX (Abbott Medical Optics, Santa Ana, CA, USA); and group II, torsional phaco with OZil ${ }^{\circledR}$ Intelligent Phaco (Bausch and Lomb, Rochester, NY, USA).

edema, and corneal endothelium. ${ }^{1,5,7-12,19,20}$ However, to date, only one study has compared longitudinal, torsional, and transversal phaco. ${ }^{5}$ In that study, the clinical outcomes with three different phaco platforms were evaluated: WhiteStar Signature $^{\circledR}$ Ellips $^{\text {TM }}$ FX (transversal), Infiniti ${ }^{\circledR}$ OZil $^{\circledR}$ IP (torsional), and Stellaris ${ }^{\circledR}$ (longitudinal). Those authors found that the torsional machine had less phaco needle time, less chatter, better followability, and yielded less central corneal edema than the transversal or longitudinal machines. However, they did not compare the effect of using the platforms in terms of the corneal endothelium. The aim of the current study was to compare and evaluate the corneal morphological changes, including endothelial modifications, as an indicator of safety for cataract surgery through a $2.2 \mathrm{~mm}$ corneal incision. This study compared and evaluated the transversal and torsional phaco platforms.

Because of different algorithms adopted by the two platforms, the current comparative analysis did not measure the effective phaco time, cumulative dissipated energy, phaco time, or balanced salt solution consumption. Georgescu et $\mathrm{al}^{17}$ demonstrated that a comparable unoccluded flow vacuum of $60 \mathrm{~mL} / \mathrm{min}$ would correspond with approximately $220 \mathrm{mmHg}$ and $120 \mathrm{mmHg}$ for the Infiniti ${ }^{\circledR}$ and WhiteStar Signature ${ }^{\circledR}$ platforms, respectively. Our comparative analysis preferred the use of independent and more clinically significant parameters, such as wound stretch, corneal edema, endothelial cell loss, pleomorphism, and central pachymetry.
The function of followability is to bring free nuclear fragments close to the phaco tip for continuous and smoothly progressive emulsification and aspiration. Fluidic models have shown that the longitudinal movement repels lens material from the tip, whereas the rotational motion of torsional US reduces the repulsion of the lens fragments, thus improving followability of nuclear material into the phaco tip. ${ }^{20}$ Longitudinal phaco tip movement repels lens matter with every stroke. Conversely, lateral movement reduces repulsion of the lens fragments, thus improving followability during phaco. In transversal phaco, nuclear fragments are exposed to shearing stress and the jackhammering effect caused by the transversal and longitudinal motion, respectively, but without the repulsion seen in longitudinal phaco. Furthermore, with the Ellips ${ }^{\mathrm{TM}}$ FX, the longitudinal US could not be separated from the transversal component. With the OZil ${ }^{\circledR}$ IP, the longitudinal component might be switched off or set to an automatic activation when a preset threshold vacuum was reached. For this reason, a better followability was expected in the torsional group than the transversal group. However, both systems showed improved and comparable followability.

Georgescu et $\mathrm{al}^{17}$ demonstrated that the postocclusion surge (POS) was significantly worse for the Infiniti ${ }^{\circledR}$ platform than for the WhiteStar Signature ${ }^{\circledR}$ platform. However, this could only be clinically important in extreme experimental conditions, such as using $60 \mathrm{~mL} / \mathrm{min}$ of flow, a $550 \mathrm{mmHg}$ 
vacuum, and a bottle height of $60 \mathrm{~cm}$. POS is often at its worst when dealing with a broken capsule and corneal endothelial damage. ${ }^{17}$ According to the settings used in our study, we expected the POS to be negligible. Indeed, no POS was noticed during surgery in either of our groups.

Regarding corneal incision size before IOL implantation, no statistically significant differences were found between the groups. The minimal wound stretch found in group I may be attributable to the compliant nature of the sleeve and the microvoid between the phaco tip and incision. Hence, the transversal movement of the phaco tip did not induce wound stress or burn. It should be noted that the new, ultrasleeve $21 \mathrm{G}$ tip was used with the Ellips ${ }^{\mathrm{TM}} \mathrm{FX}$ in our study. This use was off-label, due to its commercial unavailability at the beginning of the study. As for group II, our results were consistent with previous scientific evidence. Han and Miller ${ }^{19}$ reported that torsional phaco created less heat than longitudinal phaco. In concordance with this, Jun et $\mathrm{al}^{10}$ stated that the smaller incision phaco of torsional US may decrease the risk for wound burn in eyes with denser cataracts. Furthermore, Li et $\mathrm{al}^{21}$ have recently demonstrated that, in the context of torsional phaco, a micro-coaxial, $2.2 \mathrm{~mm}$ incision may cause slightly less damage than the $2.8 \mathrm{~mm}$ standard incision. Therefore, considering the twist movement of the phaco tip in torsional US and considering that the mini-flare tip and ultra-sleeve used in group II were designed to fit $2.2 \mathrm{~mm}$ and $2.4 \mathrm{~mm}$ incisions, the minimal wound stretch found in this group seems to be a coherent finding. Finally, the enhanced followability with the torsional phaco mode reduced the additional hand-piece movements to reacquire the nuclear fragments, minimizing the stretch in the incision. ${ }^{20}$

The mean endothelial cell loss in the current study was $1.7 \%$ and $2.0 \%$ in groups I and II, respectively. These values were better than those obtained in other studies using the torsional technology. 8,9 This may be attributable to the use of an improved technology, the different surgical technique, the ophthalmic viscoelastic device used, and the different classification system adopted (LOCS III vs LOCS II). One study found an endothelial cell loss of $7.2 \% \pm 4.6 \%$ using the torsional phaco technology through a $2.75 \mathrm{~mm}$ clear corneal incision, ${ }^{9}$ yet, in our study, no significant differences between groups were observed in endothelial cell loss, CV, and hexagonality, confirming the presence of similar postoperative levels of polymegathism and pleomorphism in both groups. Therefore, the same minimal level of endothelial damage seems to be induced with both phaco technologies.

It has been postulated that a longer phaco time ${ }^{22,23}$ and higher US power ${ }^{22}$ are associated with endothelial cell loss, although some studies failed to prove these correlations. ${ }^{9,24,25}$ Reuschel et $\mathrm{al}^{9}$ found a statistically significant difference in US energy and time between the torsional and longitudinal phaco, but there was no significant correlation between these parameters and endothelial cell loss. In addition, the cell loss was not significantly different between the two groups. ${ }^{9}$ In the current study, a more significant endothelial cell loss would have been expected in the Ellips ${ }^{\text {TM }}$ FX group, since the longitudinal movement component of the tip was constantly present, yet this finding was not obtained. This suggests that we have approached the critical value for safe phaco modality with the currently available torsional and transversal phaco technology, beyond which no significant improvements in endothelial cell protection can be observed. Future studies are required to confirm this hypothesis.

We also found a minimal, but statistically significant increase of 28.1 and $24.0 \mu \mathrm{m}$ in CCT in groups I and II, respectively. The difference between the groups in this minimal level of corneal edema did not reach statistical significance. However, Christakis and Braga-Mele ${ }^{5}$ found that torsional technology yielded less central corneal edema than the transversal and longitudinal technologies, corresponding to a smaller increase in the mean corneal thickness (torsional, $5 \%$; transversal, $10 \%$; longitudinal, $12 \%$ ). One of the main factors accounting for this discrepancy with our findings may be the difference in the nuclear cataract grade, which was NC $2.0 \pm 0.8$ in Christakis and Braga-Mele’s study. ${ }^{5}$

\section{Conclusion}

Ellips ${ }^{\mathrm{TM}} \mathrm{FX}$ transversal and $\mathrm{OZil}{ }^{\circledR}$ IP torsional phaco platforms are safe for performing cataract surgery, inducing minimal corneal thickness and endothelial changes. In terms of followability, the effect on the endothelium and the corneal incision, and the induced corneal thickness increase, both technologies seem to be equivalent for extraction of an NC 2-4 (LOCS III) cataract through a $2.2 \mathrm{~mm}$ incision. Future optical coherence tomography studies are needed to compare the effects of torsional and transversal phaco types on the corneal incision. In addition, the potential benefits and applicability of these technologies in eyes with a compromised endothelium should be further evaluated.

\section{Disclosure}

The authors report no conflicts of interest in this work.

\section{References}

1. Liu Y, Zeng M, Liu X, et al. Torsional mode versus conventional ultrasound mode phacoemulsification: randomized comparative clinical study. J Cataract Refract Surg. 2007;33:287-292. 
2. Hoffman RS, Fine IH, Packer M. New phacoemulsification technology. Curr Opin Ophthalmol. 2005;16:38-43.

3. Vargas LG, Holzer MP, Solomon KD, Sandoval HP, Auffarth GU, Apple DJ. Endothelial cell integrity after phacoemulsification with two different handpieces. J Cataract Refract Surg. 2004;30:478-482.

4. Rosado-Adames N, Afshari NA. The changing fate of the corneal endothelium in cataract surgery. Curr Opin Ophthalmol. 2012;23:3-6.

5. Christakis PG, Braga-Mele RM. Intraoperative performance and postoperative outcome comparison of longitudinal, torsional, and transversal phacoemulsification machines. J Cataract Refract Surg. 2012;38:234-241.

6. Park YG, Chung SH, Joo CK. Comparison of micro-coaxial with standard clear corneal incisions in torsional handpiece cataract surgery. Ophthalmologica. 2012;227:55-59.

7. Fakhry MA, El Shazly MI. Torsional ultrasound mode versus combined torsional and conventional ultrasound mode phacoemulsification for eyes with hard cataract. Clin Ophthalmol. 2011;5:973-978.

8. Kim DH, Wee WR, Lee JH, Kim MK. The comparison between torsional and conventional mode phacoemulsification in moderate and hard cataracts. Korean J Ophthalmol. 2010;24:336-340.

9. Reuschel A, Bogatsch H, Barth T, Wiedemann R. Comparison of endothelial changes and power settings between torsional and longitudinal phacoemulsification. J Cataract Refract Surg. 2010;36:1855-1861.

10. Jun B, Berdahl JP, Kim T. Thermal study of longitudinal and torsional ultrasound phacoemulsification: tracking the temperature of the corneal surface, incision, and handpiece. J Cataract Refract Surg. 2010;36: 832-837.

11. Vasavada AR, Raj SM, Patel U, Vasavada V, Vasavada V. Comparison of torsional and microburst longitudinal phacoemulsification: a prospective, randomized, masked clinical trial. Ophthalmic Surg Lasers Imaging. 2010;41:109-114.

12. Rekas M, Montes-Mico R, Krix-Jachym K, Klus A, Stankiewicz A, Ferrer-Blasco T. Comparison of torsional and longitudinal modes using phacoemulsification parameters. J Cataract Refract Surg. 2009;35: 1719-1724.

13. Zeng M, Liu X, Liu Y, et al. Torsional ultrasound modality for hard nucleus phacoemulsification cataract extraction. Br J Ophthalmol. 2008;92:1092-1096
14. Ratnarajan G, Packard R, Ward M. Combined occlusion-triggered longitudinal and torsional phacoemulsification during coaxial micro-incision cataract surgery: effect on 30-degree mini-flared tip behavior. J Cataract Refract Surg. 2011;37:825-829.

15. Tognetto D, Cecchini P, Leon P, Di Nicola M, Ravalico G. Stroke dynamics and frequency of three phacoemulsification machines J Cataract Refract Surg. 2012;38:333-342.

16. Schmutz JS, Olson RJ. Thermal comparison of Infiniti OZil and Signature Ellips phacoemulsification systems. Am J Ophthalmol. 2010;149: 762-767.

17. Georgescu D, Kuo AF, Kinard KI, Olson RJ. A fluidics comparison of Alcon Infiniti, Bausch and Lomb Stellaris, and Advanced Medical Optics Signature phacoemulsification machines. Am J Ophthalmol. 2008;145:1014-1017.

18. Chylack LTJ, Wolfe JK, Singer DM, et al. The lens opacities classification system III. Arch Ophthalmol. 1993;111:831-836.

19. Han YK, Miller KM. Heat production: longitudinal versus torsional phacoemulsification. J Cataract Refract Surg. 2009;35:1799-1805.

20. Davison JA. Cumulative tip travel and implied followability of longitudinal and torsional phacoemulsification. J Cataract Refract Surg. 2008;34:986-990.

21. Li YJ, Kim HJ, Joo CK. Early changes in corneal edema following torsional phacoemulsification using anterior segment optical coherence tomography and Scheimpflug photography. Jpn J Ophthalmol. 2011;55: 196-204.

22. O'Brien PD, Fitzpatrick P, Kilmartin DJ, Beatty S. Risk factors for endothelial cell loss after phacoemulsification surgery by a junior resident. J Cataract Refract Surg. 2004;30:839-843.

23. Walkow T, Anders N, Klebe S. Endothelial cell loss after phacoemulsification: relation to preoperative and intraoperative parameters. J Cataract Refract Surg. 2000;26:727-732.

24. Kosrirukvongs P, Slade SG, Berkeley RG. Corneal endothelial changes after divide and conquer versus chip and flip phacoemulsification. J Cataract Refract Surg. 1997;23:1006-1012.

25. Zetterstrom C, Laurell CG. Comparison of endothelial cell loss and phacoemulsification energy during endocapsular phacoemulsification surgery. J Cataract Refract Surg. 1995;21:55-58.
Clinical Ophthalmology

\section{Publish your work in this journal}

Clinical Ophthalmology is an international, peer-reviewed journal covering all subspecialties within ophthalmology. Key topics include: Optometry; Visual science; Pharmacology and drug therapy in eye diseases; Basic Sciences; Primary and Secondary eye care; Patient Safety and Quality of Care Improvements. This journal is indexed on

\section{Dovepress}

PubMed Central and CAS, and is the official journal of The Society of Clinical Ophthalmology (SCO). The manuscript management system is completely online and includes a very quick and fair peer-review system, which is all easy to use. Visit http://www.dovepress.com/ testimonials.php to read real quotes from published authors. 